BMJ Open

Sport \&

Exercise

Medicine

\title{
Anterior cruciate ligament injuries in Australian football: should women and girls be playing? You're asking the wrong question
}

\author{
Aaron Fox (D) , Jason Bonacci (D) , ${ }^{1}$ Samantha Hoffmann (D) , \\ Sophia Nimphius (D) , ${ }^{2,3}$ Natalie Saunders (1) ${ }^{1}$
}

To cite: Fox A, Bonacci J Hoffmann S, et al. Anterior cruciate ligament injuries in Australian football: should women and girls be playing? You're asking the wrong question. BMJ Open Sport \& Exercise Medicine 2020;6:e000778. doi:10.1136/ bmjsem-2020-000778
Check for updates

(C) Author(s) (or their employer(s)) 2020. Re-use permitted under CC BY-NC. No commercial re-use. See rights and permissions. Published by BMJ.

${ }^{1}$ Centre for Sport Research, School of Exercise and Nutrition Sciences, Deakin University, Geelong, Victoria, Australia ${ }^{2}$ Centre for Exercise and Sports Science Research, School of Medical and Health Sciences, Edith Cowan University, Joondalup, Western Australia, Australia

${ }^{3}$ Sports Performance Research Institute New Zealand, Auckland University of Technology, Auckland, New Zealand

Correspondence to Dr Aaron Fox; aaron.f@deakin.edu.au

\section{ABSTRACT}

Anterior cruciate ligament $(A C L)$ injuries have been a rising concern in the early years of the women's Australian Football League (AFLW), eliciting headlines of a 'knee crisis' surrounding the league. There has been a focus on female biology as the primary factor driving the high rate of ACL injuries in the AFLW. Emphasising Australian football (AF) as being dangerous predominantly due to female biology may be misrepresenting a root cause of the ACL injury problem, perpetuating gender stereotypes that can restrict physical development and participation of women and girls in the sport. We propose that an approach addressing environmental and sociocultural factors, along with biological determinants, is required to truly challenge the ACL injury problem in the AFLW. Sports science and medicine must therefore strive to understand the whole system of women in AF, and question how to address inequities for the benefit of the athletes.

The Australian Football League (AFL) is the major elite men's competition for Australian football $(\mathrm{AF})$ and represents the pinnacle of the sport. In 2017, the AFL took the step of introducing an elite women's league (ie, the Australian Football League Women's (AFLW)) to their competition. While the introduction of this league has been viewed as a success, ${ }^{1}$ the high rate of injury in the competition has not gone unnoticed. In particular, anterior cruciate ligament (ACL) injuries are acknowledged as a rising concern in the AFLW, with rates 6.2 and 9.2 times higher in the women's first two seasons compared with the men's AFL across the same years (4.31 vs 0.7 and 6.47 vs 0.7 per 1000 player hours in 2017 and 2018, respectively). The AFLW saw a drop in the rate of ACL injuries in the 2019 season (5.14 per 1000 player hours); however, this rate remains substantially higher than other female sports. ${ }^{23}$ The high rate of ACL injuries in the AFLW has been a drawcard for media attention. The 2019 AFLW season elicited media headlines of a "knee crisis'4

\section{Key points}

- The common suggestion that 'biology' is a primary factor in the high-rate of anterior cruciate ligament (ACL) injuries in women's Australian football (AF) may be misrepresenting a root cause of the ACL injury problem.

- The relative infancy of women and girls participating in $\mathrm{AF}$, limited experience during youth and reduced access to facilities, training opportunities and medi$\mathrm{cal} /$ athletic development staff are potential environmental and sociocultural drivers for differences in ACL injury rates between the men's and women's AFL competitions.

- Evidence suggests that an approach addressing environmental, sociocultural and biological factors is required to comprehensively address the ACL injury problem in women's AF.

after five ACL injuries in the first five rounds. A similar scenario appears to be playing out in the 2020 season, where three players sustained season ending ACL injuries in the first round of competition, and a total of 12 have been recorded in the first four rounds of the season. Female biology is often stipulated as a primary factor in the ACL injury problem in the AFLW. Comments suggesting athletes with female biology are 'made differently' and 'more prone to do knees', 4 or that 'female hormones may be related to injury ${ }^{5}$ are promoted as explanations. $\mathrm{AF}$ and the AFLW $^{\mathrm{i}}$ are important vehicles for ongoing participation of women and girls in sport. Women and girls account for nearly one-third of the $1649178 \mathrm{AF}$ players nationally, with the number of clubs with women's or girl's teams doubling from 2016 to 2018. ${ }^{1}$ Media attention emphasising $\mathrm{AF}$ as being dangerous for women and girls due to their 'biology' may be misrepresenting a root cause of the ACL injury problem, perpetuating gender 
stereotypes that can restrict physical development and participation of women and girls in sport.

\section{A BIOLOGICAL PROBLEM, OR SOMETHING ELSE?}

A higher rate of ACL injuries in women over men has been observed in other sports, ${ }^{23}$ with the supposition that differences due to biological sex leads to hazardous neuromechanical strategies being employed during sporting tasks. ${ }^{6}$ However, this notion has been questioned in systematic reviews of the evidence ${ }^{78}$ and takes a myopic view that biological differences would solely explain such disparity, with no consideration of environmental and sociocultural differences due to gendered experiences.

The relative infancy of participation by women and girls in AF results in many AFLW players having limited to no AF experience during their youth. In 2019, AFLW teams were also required to have at least two 'cross-code rookies' (ie, not played organised AF for the past 3 years), a stark contrast to the typically lifelong developmental experience of men in the AFL. The combination of reduced sport-specific motor skill development acquired through deliberate practice, ${ }^{9}$ along with very short preseason training periods for the AFLW, could create a 'perfect storm' of athletes with higher risk of ACL injury in a 'new' sport encompassing high-risk tasks.

AFLW players earned between \$A13400 and \$A24600 in the 2018 season. ${ }^{1}$ The AFLW involves a condensed schedule (eg, in 2019, the AFLW season included seven rounds plus 2 weeks of finals compared with the 23 rounds plus 4 weeks of finals in the men's competition), and subsequently AFLW salaries meet the minimum pay standards of the men's competition on a pro rata basis. However, a significant pay gap still exists between the two competitions. Even the highest payment tier of an AFLW salary does not meet the minimum wage requirement in Australia (ie, \$A719.20 per week, equating to $\$$ A37398.40 per annum), whereas the minimum base payment (\$A75 $000)$ and average wage ( $\$$ A362 471) for the $\mathrm{AFL}^{1}$ substantially exceeds minimum wage. AFLW players are likely managing training commitments with other employment, leading to reduced access to facilities, training opportunities and medical/athletic development staff. Additional financial support and access to environments that bridge the gap between men's and women's AF can maximise opportunities to prepare players to meet the sport demands.

\section{WHAT HAPPENS WHEN THESE ISSUES ARE ADDRESSED?}

There is evidence to support the notion that addressing differences in experience, skill and conditioning can contribute to minimising sex differences in ACL injury rates and risk factors. Dance is an athletic profession where similar training age and opportunity are observed between genders. ${ }^{10}$ Dancers accumulate practice in landing technique throughout youth, and despite incorporating similar high-risk movements and training loads, the disparity in ACL injury rates is not present. ${ }^{11}$ Female dancers also do not display hazardous landing strategies associated with ACL injury when compared with male dancers or team-sport athletes. ${ }^{12} 13$ Orishimo et $a l^{13}$ observed similar landing biomechanics between male and female dancers and found a relationship between the age at which dancers began training and the frontalplane hip angle (ie, a noted component of the 'dynamic valgus' collapse linked to the ACL injury mechanism ${ }^{14}$ ) during landing. A later study by the same group observed that dancers of both sexes exhibited similar frontalplane knee mechanics during landing to male team sport athletes. ${ }^{12}$ In contrast, female team sport athletes landed with greater knee valgus angles compared with dancers and male team sport athletes. ${ }^{12}$ Together, these findings suggest that the potential 'female-specific' hazardous landing pattern may not be driven by sex, but rather training age and exposure. Reviews collating the evidence for sex differences in landing ${ }^{8}$ and side-step cutting $^{7}$ biomechanics have observed inconsistent findings across the literature, perhaps due to the sex-specific cohorts being unmatched on factors such as training age, skill level or strength. This view is supported by a recent study which found that neuromuscular differences between female and male participants that potentially contribute to the disparity in ACL injury rates vastly reduce when controlling for relative muscular strength and training age. ${ }^{15}$ While limited, the available evidence suggests that when equality in opportunity, experience and training age exists, the commonly observed disparity in ACL injury rates and risk factors between female and male athletes vastly reduces or disappears.

\section{WHAT QUESTIONS SHOULD WE BE ASKING?}

Participation of women and girls in AF and the knee crisis has brought ACL injuries to the forefront of sports medicine in Australia. Other team sports (eg, basketball and soccer) with longer histories have already encountered this problem. Despite persistent efforts across sports, the disparity in ACL injury rates between female and male athletes has persisted for decades. ${ }^{23}$ A continued focus on biological sex determinants is problematic. Evidence suggests that an approach encompassing environmental and sociocultural factors, along with biological determinants, is required. If we continue to catastrophise ACL injury in AFLW, we may discourage women and girls from participating in the sport. Women in sport has been catastrophised before; until 1972, women could not officially enter the Boston marathon for fear their physiology could not withstand the demand! AF must avoid repeating these mistakes. Sports science and medicine must strive to better understand the whole of system development of female athletes in $\mathrm{AF}$, but also other sports where sex disparities in ACL injuries are observed (eg, soccer, basketball and handball). We must question how to address the inequities in player development and training opportunities, financial support, and access to facilities and professional staff. Instead of asking whether women and girls should play AF, we must ask what we can do to address the system leading to ACL injuries to 
women in $\mathrm{AF}$ so that women and girls can continue to play, and do so safely. Only after maximising long-term development opportunities for these players can we begin to address any outstanding ACL injury problem.

i. AF refers to the football code, while AFLW and AFL refer to names of the elite women's and men's competitions, respectively.

Twitter Aaron Fox @aaron_s_fox

Contributors All authors contributed to this viewpoint article. AF and NS wrote the initial draft. JB, SH and SN provided feedback on the initial draft. All authors have read and commented on the draft version and approved the final version of the manuscript.

Funding The authors have not declared a specific grant for this research from any funding agency in the public, commercial or not-for-profit sectors.

Competing interests None declared.

Patient consent for publication Not required.

Provenance and peer review Not commissioned; externally peer reviewed.

Open access This is an open access article distributed in accordance with the Creative Commons Attribution Non Commercial (CC BY-NC 4.0) license, which permits others to distribute, remix, adapt, build upon this work non-commercially, and license their derivative works on different terms, provided the original work is properly cited, appropriate credit is given, any changes made indicated, and the use is non-commercial. See: http://creativecommons.org/licenses/by-nc/4.0/.

\section{ORCID iDs}

Aaron Fox http://orcid.org/0000-0002-5639-6388

Jason Bonacci http://orcid.org/0000-0002-4333-3214

Samantha Hoffmann http://orcid.org/0000-0001-8824-7531

Sophia Nimphius http://orcid.org/0000-0002-3524-0245

Natalie Saunders http://orcid.org/0000-0001-9177-5896

\section{REFERENCES}

1 Australian Football League. 2018 annual report, 2018.
2 Agel J, Rockwood T, Klossner D. Collegiate ACL injury rates across 15 sports. Clin J Sport Med 2016;26:518-23.

3 Hootman JM, Dick R, Agel J. Epidemiology of collegiate injuries for 15 sports: summary and recommendations for injury prevention initiatives. J Athl Train 2007;42:311-9.

4 Sewell E. Knee crisis growing. herald sun, February 9th 2019.

5 Wood L. Acl link probe. herald sun, February 182020.

6 Hewett TE, Myer GD, Ford KR. Anterior cruciate ligament injuries in female athletes: Part 1, mechanisms and risk factors. Am J Sports Med 2006;34:299-311

7 Benjaminse A, Gokeler A, Fleisig GS, et al. What is the true evidence for gender-related differences during plant and cut maneuvers? A systematic review. Knee Surg Sports Traumatol Arthrosc 2011;19:42-54.

8 Beaulieu ML, McLean SG. Sex-dimorphic landing mechanics and their role within the noncontact $A C L$ injury mechanism: evidence, limitations and directions. BMC Sports Sci Med Rehabil 2012;4:10.

9 Bruton MR, O'Dwyer N, Adams R. Sex differences in the kinematics and neuromuscular control of landing: biological, environmental and sociocultural factors. J Electromyogr Kinesiol 2013:23:747-58

10 Weiss DS, Shah S, Burchette RJ. A profile of the demographics and training characteristics of professional modern dancers. J Danc Med Sci 2008:12:41-6.

11 Liederbach M, Dilgen FE, Rose DJ. Incidence of anterior cruciate ligament injuries among elite ballet and modern dancers. Am J Sports Med 2008;36:1779-88.

12 Orishimo KF, Liederbach M, Kremenic IJ, et al. Comparison of landing biomechanics between male and female dancers and athletes, part 1: influence of sex on risk of anterior cruciate ligament injury. Am J Sports Med 2014;42:1082-8.

13 Orishimo KF, Kremenic IJ, Pappas E, et al. Comparison of landing biomechanics between male and female professional dancers. Am J Sports Med 2009;37:2187-93.

14 Hewett TE, Myer GD, Ford KR, et al. Biomechanical measures of neuromuscular control and valgus loading of the knee predict anterior cruciate ligament injury risk in female athletes: a prospective study. Am J Sports Med 2005;33:492-501.

15 Nimphius S, McBride JM, Rice PE, et al. Comparison of quadriceps and hamstring muscle activity during an isometric squat between Strength-Matched men and women. J Sports Sci Med 2019;18:101-8. 